\title{
Psicologia e Ruralidades no Brasil: Contribuições para o Debate
}

\author{
Kátya de Brito e Silva \\ Universidade Federal do Piauí, PI, Brasil.
}

\author{
João Paulo Macedo \\ Universidade Federal do Piauí, PI, Brasil.
}

\begin{abstract}
Resumo: O tema das ruralidades é um novo campo teórico de discussão para Psicologia, especialmente para aqueles que estão inseridos profissionalmente no âmbito das políticas públicas, nos chamados municípios de pequeno porte, marcados pela forte presença dos meios e povos rurais nos seus territórios. Apesar disso, há uma carência de estudos no âmbito da Psicologia brasileira que trate sobre o tema. Objetivamos com este ensaio delinear as principais categorias teóricas e analíticas que possam contribuir para estabelecer um profícuo diálogo entre a Psicologia e os estudos rurais no Brasil. Metodologicamente, localizamos, na trajetória da reflexão brasileira sobre rural e povos rurais, as principais contribuições teóricas e críticas sobre rural; em seguida, situamos essa discussão na produção psicológica brasileira que trata sobre o tema, conduzindo o leitor a uma reflexão acerca dos desafios e interpelações vivenciadas no encontro com os povos e meios rurais. Assim, evidencia-se a importância de destacar a construção de um recorte crítico capaz de fortalecer a discussão acerca da presença da Psicologia no mundo rural. Do mesmo modo, com a consolidação desse campo, espera-se que essa aproximação também fortaleça o lugar da Psicologia, enquanto ciência e profissão, em meio a diferentes disciplinas que constituem os estudos rurais no Brasil.
\end{abstract}

Palavras-chave: Psicologia, Ruralidades, Estudos Rurais.

\section{Psychology and Ruralities in Brazil: Contributions for the Debate}

Abstract: The theme of ruralities is a new theoretical field of discussion for psychology, especially for those professionally involved with public policies, in cities considered small, characterized by the strong presence of rural people and fields in their territories. In spite of it, there is a lack of studies in Brazilian psychology regarding this theme. We aimed, with this essay, to outline the main theoretical and analytical categories that can contribute to establish a valuable dialogue between psychology and rural studies. Methodologically, we located the trajectory of the reflection in Brazil about rural and rural people; next, we placed this discussion in the psychological production that studies this theme, taking the reader through a reflection about the challenges and interpellations experienced in the encounter with rural environments and people. Thus, the importance of constructing a critical clipping about the presence of psychology in the rural context is highlighted. In the same way, with the consolidation of this field, it is expected that this approximation also strengthens psychology's place as science and profession, among the different disciplines that constitute rural studies in Brazil.

Keywords: Psychology, Ruralities, Rural Studies. 


\title{
Psicología y Ruralidades en Brasil: Contribuciones al Debate
}

\begin{abstract}
Resumen: El tema de las ruralidades es un nuevo campo de discusión teórico de la psicología, especialmente para aquellos que se insertan profesionalmente en el ámbito de las políticas públicas, en los llamados pequeños pueblos, marcados por la fuerte presencia de los medios y las personas rurales en sus territorios. Sin embargo, hay una falta de estudios en el campo de la psicología brasileña sobre el tema. Nuestro objetivo en este ensayo es delinear las principales categorías teóricas y analíticas que puedan contribuir a un diálogo fructífero entre la psicología y los estudios rurales en Brasil. En cuanto a la metodología, nos encontramos en la trayectoria de la reflexión brasileña sobre lo rural y las personas rurales, las principales contribuciones teóricas y críticas sobre lo rural; después, situamos esta discusión en la producción psicológica brasileña que trata del tema, llevando el lector a una reflexión sobre los desafíos e interpelaciones experimentados en el encuentro con las personas y los medios rurales. Así, es evidente la importancia de destacar la construcción de un corte crítico que fortalezca la discusión sobre la presencia de la psicología en el mundo rural. Del mismo modo, con la consolidación de este campo, se espera que esta aproximación también fortalezca el lugar de la psicología, como ciencia y profesión, en el medio de las diferentes disciplinas que integran los estudios rurales en Brasil.
\end{abstract}

Palabras clave: Psicología, Ruralidades, Estudios Rurales.

\section{Introdução}

Em termos teóricos e analíticos, o debate sobre rural envolve múltiplas contribuições das mais diversas áreas do conhecimento, chegando, inclusive, a incorporar em seus programas de estudos e pesquisas o rural enquanto subárea, a exemplo da sociologia rural e da econômica agrária, constituindo ramos de conhecimento bem estabelecidos e aceitos pela comunidade científica (Albuquerque, 2001).

No âmbito da Psicologia, apesar de visualizarmos maior presença profissional junto aos contextos rurais nos últimos anos, por meio da integração dos psicólogos junto às equipes multiprofissionais da atenção primária e psicossocial do Sistema Único de Saúde (SUS) e da Proteção Social Básica do Sistema Único da Assistência Social (SUAS) (Leite, Macedo, Dimenstein, \& Dantas, 2013; Macedo, \& Dimenstein, 2011), além das experiências relacionadas à extensão rural e à educação no campo (Landini, et al., 2015), observa-se certa ausência de um corpo organizado de conhecimentos que situe as várias discussões envolvendo aspectos teóricos, metodológicos e analíticos dos estudos rurais, no sentido de qualificar o olhar e atuações profissionais dos(as) psicólogos(as) que atuam nessas realidades.

Por esse aspecto, o debate sobre rural tem margeado a produção científica na Psicologia brasileira e de certa forma também a internacional (Albuquerque, 1996; 2001), sendo que em muitas publicações , conforme indica o autor, ainda persiste a visão urbana sob os estudos em meios rurais no âmbito da Psicologia. Nesse sentido, Landini et al. (2015) alertam que envolver o rural em atividades de pesquisa implica deter-se sobre as características próprias e a heterogeneidade que marcam os meios e os povos rurais e suas relações com o urbano: ethos "rural", níveis de organização social, política e comunitária, trabalho, formas de adoecimento, processos educativos, relações familiares, cultura, regras sociais, atitudes, valores, sociabilidades etc.

Apesar de soar "estranho" falar de uma "Psicologia Rural”, como bem frisou Landini et al. (2015), até mesmo pelas controvérsias implícitas sobre as compreensões do que seja rural, nos últimos anos houve um crescente interesse sobre fenômenos psicológicos e psicossociais que acontecem em contextos rurais. Porém, é preciso compreender de que maneira tem se dado essa aproximação entre Psicologia e ruralidades, inclusive para nortear agendas de pesquisa neste promissor campo de interesses e temas de investigação.

Deste modo, propomos neste ensaio apresentar, com base na literatura que trata sobre os estudos rurais no Brasil, as principais contribuições e críticas sobre rural, no objetivo de delinear categorias teóricas e analíticas que possam contribuir para estabelecer um profícuo diálogo com a Psicologia. O texto 
está organizado, em termos metodológicos, de modo a localizarmos a trajetória da reflexão brasileira sobre o tema, para em seguida, situá-lo na Psicologia, conduzindo o leitor a uma reflexão acerca dos desafios e interpelações vivenciadas no encontro com os povos e meios rurais.

\section{Trajetória da reflexão brasileira sobre rural: breves considerações}

No Brasil, o chamado meio rural tem sido pensado por uma ampla produção que perpassa diversas áreas do conhecimento. Disciplinas como Sociologia, Antropologia, Agronomia, Economia e Geografia têm produzido vários entendimentos e matizes analíticas para a compreensão sobre o rural enquanto importante categoria de reflexão teórica sobre territórios, identidades, modos devida, campos de disputa política e econômica, atividades produtivas e transformações/alternativas que conformam os meios rurais brasileiros.

Como lembra Queiroz (1973 citado por Moraes, \& Vilela, 2013), foi na passagem do século XIX para o século XX que o rural se tornou objeto de estudo. É preciso entender que nesse período foi elaborado no campo sociológico uma lógica binária de sociedade, na qual rural era caracterizado como "atrasado, tradicional, selvagem, incivilizado, resistente a mudanças, etc." (Moreira, 2005, p. 19) e urbano como sinônimo de modernização, portanto, centro da sociedade (Carmo, 2009). Essa visão dualista teve forte influência nos estudos realizados nesse período (Camargo, \& Oliveira, 2012; Carmo, 2009; Moreira, 2005; Wanderley, 2000).

Cabe o registro que foi a partir da sociologia rural norte-americana, mais precisamente entre a década de 1920 e 1930, que o rural se tornou um problema de pesquisa particular e objeto de investigação sociológica, consolidando-se teórica e metodologicamente no âmbito das ciências sociais. Data dessa época a primeira abordagem sobre o rural, a partir da perspectiva do continnum urbano-rural, considerada uma variação analítica da abordagem dualista da relação campo-cidade, em que o rural acabava sendo entendido como resíduo (Blume, 2004).

A esse respeito, uma das interpretações sobre o continnum urbano-rural, realizada por Sorokin, Zimmermann e Galpin (1981), entendia a existência de um gradiente de variações espaciais, de maneira que se vai de uma situação (rural) a outra (urbano), constituindo relações de contato e gradação entre ambas, espécie de continuidade entre os dois espaços, porém, resguardadas as particularidades que os define. Os autores estabeleceram nove diferenças fundamentais entre rural e urbano, sendo as ocupacionais as principais, derivando para as demais ${ }^{1}$.

Ainda no contexto mundial, de 1950 a meados de 1970, surge nova compreensão, em que o rural passou a ser percebido como sinônimo de agrícola, muito em função do modelo de desenvolvimento rural produtivista. No Brasil, assim como em outros países, este modelo foi direcionador da abordagem difusionista amplamente adotado pela Assistência Técnica e Extensão Rural (ATER). O difusionismo ou diffusion research surgiu a partir dos estudos da sociologia rural americana, com base em conhecimentos de cunho psicológico-behaviorista, em que tomava o "agricultor como um ator que respondia aos estímulos das novas tecnologias, da educação e oportunidades ocupacionais" (Schneider, 1997, p. 227). Desloca-se, portanto, o foco para os agricultores, no tocante as suas atitudes, valores, aspirações, enfim, características psicossociais e comportamentais, para difusão e adoção de novas tecnologias de produção e práticas agrícolas (Linder, Alves, \& Ferreira, 2009).

Com a crise da rural sociology em 1970, surge, dentre outras posições, uma terceira abordagem, com pensamento contrário e de negação aos pressupostos da sociologia rural, que ficou conhecida como sociologia da agricultura. O objetivo era substituir os estudos sobre rural pelos da agricultura, tendo como objeto de investigação as relações sociais que ocorrem na (ou a partir da) atividade agrícola (Blume, 2004). A crítica também se centrava no fato do rural figurar apenas como valor ou referência empírica, e não como categoria de análise ou conceito analítico das relações que o constitui (Schneider, 1997). Caberia então à sociologia da agricultura delimitar seu campo de estudo e seu aporte teórico-conceitual, a fim de consolidar sua perspectiva crítica em torno dos temas comuns que têm conformado certa agenda de investigação em torno das "condições sociais e econômicas de existência da agricultura familiar", "políticas públicas e crise agrícola mundial", "relações de trabalho na agricultura"; "reestruturação das economias capitalistas, o comércio de commodities agrícolas", "análise das

${ }^{1}$ Consultar o trabalho de Sorokin et al. (1981) para maior aprofundamento. 
classes sociais na agricultura"; "problemática ambiental", dentre outros (Schneider, 1997, p. 249).

Por partir de um enfoque político-econômico de análise pluralista, o debate proposto pela sociologia da agricultura acabou ampliando sua compreensão sobre o rural para além das práticas agrícolas, devido às transformações do meio agrário e o fenômeno da pluriatividade ${ }^{2}$ das últimas décadas, desencadeando maior variedade de sentidos do que seja rural. Assim, a agenda de interesse da sociologia da agricultura acabou incorporando novamente este debate com base nos estudos sobre ruralidade (Blume, 2004).

Com base nessa contextualização, identifica-se que nos anos 1980 houve um salto nos estudos rurais no Brasil. Nessa época, a problemática do mundo rural na sociedade brasileira demonstrou dimensões positivas, como o caráter multidisciplinar do corpo teórico, espaços de debate e estímulo à pesquisa, diálogo com pesquisadores e centros acadêmicos de outros países, proximidade com os movimentos sociais e fundamentação em pesquisas de campo (Wanderley, 2011).

Seguiu-se, nos anos 1990, mudanças nas análises sociológicas sobre o rural brasileiro. Entre elas, sobressaiu-se a dissociação entre rural e agrícola, aspecto que prevalecia nos estudos anteriores (Brumer, \& Santos, 2006). Esse deslocamento de foco da agricultura e da dicotomia entre rural e urbano pode ser encontrado na obra de Graziano da Silva ${ }^{3}$ em sua perspectiva sobre o novo rural (Silva, 1982; 1987; 1997), com a valorização da pluriatividade, questões ecológicas, cultura country, desenvolvimento do lazer e do turismo, e da inserção de novos sujeitos (neorrurais) por meio da moradia.

A partir dessas mudanças, os estudos e pesquisas sobre o rural, ainda desencadeados e interpelados pelo fenômeno da globalização, recolocaram conceitos como espaço, território, territorialidades e territorialização, repensando as relações entre campo e cidade. Geraram-se, com isso, desafios epistemológicos, teóricos e empíricos, relativos à abertura e aprofundamento sobre processos sociais, políticos, econômicos, culturais e ambientais, que, por sua vez, envolvem diferentes atores sociais em diversas dimensões: gênero, etnia, geração, visões de mundo e modos de vida (Moraes, \& Vilela, 2013). Assim:

Extrapolando significados da construção conceitual de rural e urbano como espaços geográficos, socioeconômicos, culturais, naturais, específicos, observam-se na geografia, na economia, nas ciências sociais stricto senso, modulações significativas nas formas de pensar estas realidades, cada vez mais, relacionalmente (Moraes, \&Vilela, 2013, pp. 61-62, grifos nossos).

Por meio dessa dimensão relacional entre rural e urbano, situa-se a produção discursiva contemporânea no Brasil sobre ruralidades, tendo como marca a inflexão frente aos esquemas dualistas. Para Wanderley (2011), o que está em questão para entender o significado de ruralidade na sociedade contemporânea são as relações estabelecidas entre o mundo rural e o mundo urbano. Nas palavras de Moraes e Vilela (2013), "tomando-se rural e urbano como lugares materiais e simbólicos que se alimentam/tensionam, reciprocamente" (p.71).

A partir desse entendimento os debates acerca das relações campo-cidade assumem perspectivas que apontam para a valorização do rural e as limitações do modelo de urbanização. Além disso, consideram que apesar das indiscutíveis transformações sociais, econômicas, culturais e espaciais, não existe o fim do rural. Trata-se de um processo de alteração de significados. Rural não deixou de existir (Alentejano, 2003).

Em vez do fim do rural há uma discursividade teórica referente ao mesmo como categoria do pensamento entendida por meio de uma complexidade (Alentejano, 2003; Carneiro, 2005; Haas \& Hilling, 2009; Mattei, 2015; Moreira, 2005), tornando insuficientes caracterizações por meio de sentidos paisagísticos, formas de uso dos bens naturais e espaços geográficos ou de realização de determinadas atividades (Moraes, \& Vilela, 2013).

Com isso, novas temáticas e abordagens surgiram e têm produzido discursos sobre ruralidades

\footnotetext{
${ }^{2}$ A pluriatividade pode ser visualizada por meio de um mercado de trabalho que abarca desde a prestação de serviços manuais até o emprego temporário nas indústrias tradicionais (agroindústrias, têxtil, vidro, bebidas etc.) e pela combinação de atividades típicas do meio urbano do setor terciário com o management das atividades agropecuárias. Isso faz com que os campos passem a ser olhados como oportunidade para novos negócios (Silva, 1997; Wanderley, 2000).
}

${ }^{3}$ O professor José Graziano da Silva criou em 1996 o Projeto Rurbano. Tal projeto desenvolvido por um grupo de pesquisa demonstrou que o meio rural do final do século XX já não podia ser considerado exclusivamente agrícola. O grupo se tornou reconhecido no âmbito acadêmico e político-institucional no Brasil desde o final da década de 1990 (Schneider, 2010). 
contemporâneas. Entre as diferentes posições e sentidos, destaca-se rural enquanto um lugar específico de vida e de trabalho, sendo ampliado o olhar acerca de sua diversidade e potencialidades, relacionadas aos aspectos econômico, social, cultural, e patrimonial, que devem ser transformados em forças sociais para o desenvolvimento (Wanderley, 2001).

Seguiu-se, no debate antropológico, uma releitura do conceito de ruralidade, diluindo-se ainda mais as fronteiras entre rural e urbano. Rural foi entendido enquanto multiplicidade de modos de vida e heterogeneidades criadas por meio de diversos atores individuais e coletivos, que se apropriam de maneira diferente de bens materiais e simbólicos, conformando uma complexa rede de sociabilidades (Carneiro, 2008). Inseriu-se o debate sobre novas ruralidades, entendidas como um processo único de transformação na realidade do campo, no qual "não se pode falar de ruralidade em geral; ela se expressa de formas diferentes em universos culturais, sociais e econômicos heterogêneos" (Carneiro, 1998, p. 53).

Outra reflexão nessa mesma linha de debate sobre ruralidades contemporâneas diz respeito às expressões de identidades sociais. Parte-se de algumas hipóteses: a) a noção de identidade territorial passa por um processo de ressignificação de uma noção de território herdado da modernidade para uma nova noção associada à natureza e aos processos de produção e reprodução da vida; b) as disputas territoriais expressam diversos e diferentes interesses, como rurais e urbanos e locais/nacionais/globais, entre outros, e c) o território expressa disputas sociais e políticas nas quais são construídas identidades sociais (Moreira, 2005).

Não existe, nesse sentido, uma destruição de identidades, mas novas identificações. Aquele rural da representação da modernidade burguesa, oposto ao urbano desenvolvido e industrializado não é mais o mesmo, as relações espaço-tempo contemporâneas estariam atribuindo novos sentidos, com a possibilidade de construção de um global hegemônico desterritorializado, ou seja, sem lugar e sem território. Compreende-se uma sociabilidade mais complexa não restrita apenas ao local, mas a redes regionais, nacionais, e mesmo, transnacionais (Moreira, 2003).

Para Veiga (2006), trata-se de uma nova ruralidade na perspectiva territorial, oposta às noções de completa urbanização do rural ou de seu renascimento. Para ele:
As manifestações dessa nova ruralidade na Europa e na América do Norte não resultam de um impulso que estaria ressuscitando fundamentos de alguma ruralidade pretérita, mesmo que possam coexistir com aspectos de continuidade e permanência. $O$ que é novo nessa ruralidade pouco tem a ver com o passado, pois nunca houve sociedades tão opulentas quanto as que hoje estão valorizando sua relação com a natureza (Veiga, 2006, p. 334).

$\mathrm{Na}$ análise realizada pelo autor sobre a configuração territorial brasileira, percebe-se que o país é mais rural do que demonstram os dados oficiais: $80 \%$ dos municípios brasileiros são rurais e neles residem $30 \%$ da população brasileira. Nesse aspecto, entende que o processo de urbanização aqui é atrapalhado por uma regra que, segundo ele, é única no mundo, pois considera como urbano toda sede de município (cidade) e de distrito (vila), não importando suas características estruturais ou funcionais. Ademais, está em curso uma forte revalorização da ruralidade e não seu desaparecimento por uma suposta urbanização, sendo necessário redimensionar o tamanho e a importância da área rural brasileira assim como seu grau de urbanização (Veiga, 2001; 2007).

Para avançar na concepção territorial de ruralidades no Brasil, não se pode deixar de referir a política pública "Territórios da Cidadania" do Ministério do Desenvolvimento Agrário (MDA) que, inclusive, ajuda a promover reflexões no conceito de rural. Esse Programa, criado pelo Decreto $\mathrm{n}^{\circ} 25$ de fevereiro de 2008, objetiva a promoção do desenvolvimento econômico e universalização de programas básicos de cidadania. Isso, por meio de uma estratégia de desenvolvimento territorial sustentável. De acordo com o documento, um território rural é definido por sua identidade social, econômica e cultural, tendo como requisitos: a) conjunto de municípios com até 50 mil habitantes; b) densidade populacional menor que 80 habitantes $/ \mathrm{Km}^{2}$; c) organizados em territórios rurais de identidade; d) integrados com os Consórcios de Segurança Alimentar e Desenvolvimento Local (Consad), do Ministério do Desenvolvimento Social (MDS) e/ou Mesorregiões, do Ministério da Integração Nacional (MI). Assim, os critérios utilizados para identificação dos territórios foco da atuação do Programa foram: a) menor Índice de Desenvolvimento Humano (IDH); b) maior concentração de agriculto- 
res familiares e assentamentos da Reforma Agrária; c) maior concentração de populações quilombolas e indígenas; d) maior número de beneficiários do Programa Bolsa Família (PBF); e) maior número de municípios com baixo dinamismo econômico; f) maior organização social; g) pelo menos um território por estado da federação (Brasil, 2008).

Apesar da importância, não podemos deixar de mencionar que o Programa Territórios da Cidadania é considerado uma inovação parcial, pois os territórios ainda são percebidos como "repositório de investimentos". Assim, "como explicar, por exemplo, a ausência, no âmbito do programa, dos ministérios do Turismo, da Indústria e Comércio ou da Ciência e Tecnologia?". Seria preciso, no mínimo, superar a dicotomia entre redução da pobreza e dinamização econômica, pois apesar das obras de infraestrutura e políticas sociais ou focalizadas serem condições básicas, elas não são o bastante (Wanderley, \& Favareto, 2013, p. 445).

Por tudo isso, entende-se que as ruralidades no Brasil atual estão sendo pensadas não como realidades empiricamente observáveis, mas como uma representação social, definida culturalmente (Carneiro, 1998). Portanto, são tomadas por diferentes sentidos para além de um espaço físico e de atividades agrícolas, o que requer um exercício de construção em meio ao diverso, e não de padronização. Para essa análise, cabe considerar os vários interesses e sentidos imbricados, as diferentes abordagens conceituais e influências geradas e difundidas por distintas instituições nacionais e internacionais, e organizações multilaterais (Moraes, 2014). Exige, nesse caso, pensar os vários discursos sobre ruralidades, com concepções e sentidos diferentes e por vezes complementares, que juntos conformam um campo de disputas simbólicas (Bourdieu, 2009). Por essa perspectiva se torna possível compreender as realidades das populações que vivem nesses contextos no Brasil, um país com grande dimensão territorial e diversidade.

\section{Os povos rurais e um novo nominalismo para os estudos rurais no Brasil}

Da mesma maneira que as compreensões sobre as relações entre campo e cidade foram ampliadas, com a abertura de novas zonas de sentido sobre as ruralidades na trajetória da reflexão brasileira sobre rural, considera-se que o entendimento sobre povos rurais, em larga medida definidos pelo conceito de camponês ou de campesinidade ${ }^{4}$, também têm sido repensados.

Os estudos e pesquisas no Brasil sobre esse tema podem ser demarcados em uma tradição em torno de meio século e conta com múltiplas contribuições, que permitem caracterizar o debate contemporâneo como caudatário de ideias diversas e muitas vezes divergentes ${ }^{5}$ (Moraes, \& Vilela, 2013).

Para situar, de um modo geral, o campesinato diz respeito a uma forma social de produção, cujos fundamentos se encontram no caráter familiar, seja por conta da atividade produtiva que é voltada para as necessidades da família ou pelo modo de organização do trabalho que supõe a cooperação entre os seus membros. Trata de uma "forma de viver e de trabalhar no campo que, mais do que uma simples forma de produzir, corresponde a um modo de vida e a uma cultura" (Wanderley, 2015, p. 26). Tal caracterização é, contudo, genérica. A discussão sobre o campesinato compreende, nesse sentido, a visão de que o camponês não existe em nenhum sentido imediato ou empírico, sendo um conceito que opera no processo de conhecimento das sociedades e só pode ser entendido nesse contexto. Com isso, generalizar ou usar essa expressão de maneira indiscriminada significa desconsiderar a existência das diversas ocorrências concretas (Shanin, 2008; Velho, 2009; Wanderley, 2015; Wolf, 2003).

No caso da América Latina, para a construção de uma tipologia dos grupos camponeses, não deixaram de ser consideradas características como: transição, inter-relação, combinação e flexibilidade, entendendo que "definições são ferramentas do pensamento e não verdades eternas" (Wolf, 2003, p. 119). Para o mesmo autor, os vários tipos de campesinato baseiam-se em estruturas culturais, de maneira que as culturas camponesas são vistas como culturas parciais dentro de todos socioculturais mais extensos.

Na concepção de Wolf (2003) três distinções servem de base para a definição de camponês na América Latina: tratá-lo como produtor agrícola; distinguir entre o que detêm e o que não detêm o controle efetivo da terra; e considerar que seu objetivo é a

\footnotetext{
${ }^{4}$ Além de um conceito teórico tem um sentido político (Siqueira \& Osório, 2001).

${ }^{5}$ Foge aos propósitos e limites deste artigo aprofundar a análise acerca destas contribuições. Para isso, consultar: Wanderley (2015), Welch, Malagodi, Cavalcanti e Wanderley (2009), Woortmann (1995), Woortmann (1990).
} 
subsistência (ou aprovisionamento) e não o reinvestimento. Propôs, então, sete tipos de campesinato ${ }^{6}$, considerados como modelos provisórios, analisando mais profundamente dois deles: a comunidade camponesa corporada, que se distingue pelos seus limites nítidos; e a comunidade aberta, que enfatiza a integração ininterrupta com o mundo externo.

Trazendo para a realidade brasileira, na contemporaneidade, são considerados camponeses:

[...] proprietários e os posseiros de terras públicas e privadas; os extrativistas que usufruem os recursos naturais como povos das florestas, agroextrativistas, ribeirinhos, pescadores artesanais e catadores de caranguejos que agregam atividade agrícola, castanheiros, quebradeiras de coco-babaçu, açaizeiros; os que usufruem os fundos de pasto até os pequenos arrendatários não capitalistas, os parceiros, os foreiros e os que usufruem a terra por cessão; quilombolas e parcelas dos povos indígenas que se integram a mercados; os serranos, os caboclos e os colonos assim como os povos das fronteiras no sul do país; os agricultores familiares mais especializados, integrados aos modernos mercados, e os novos poliprodutores resultantes dos assentamentos de reforma agrária (Godoi, Meneses, \& Marin, 2009, p. 11).

Mas nem sempre se teve esse entendimento. Um breve resgate histórico demonstra que o debate sobre o campesinato no Brasil foi reativado e adotou novas conotações ao mesmo tempo da consolidação da agricultura capitalista (Wanderley, 2011). A partir dos anos 1970, com a modernização forçada do campo, houve um desenvolvimento econômico tendencioso e excludente, que introduziu na vida de suas populações um ritmo de transformação social e econômica gerador de problemas sociais, sendo que nos anos 1980 e 1990, ocorreu a grande expansão territorial do grande capital moderno (Martins, 2001).

A cidade e o campo (e as relações entre eles) foram dominados por uma racionalidade empresarial, especialmente por meio do agronegócio, que alterou estruturas sociais de poder, apropriação de espaços de vida, trabalho e produção. Ancorada na lógica do capital, na racionalidade capitalista e na tecnologia industrializada, essa racionalidade rompeu com visões e vivências tradicionais de tempo e espaço rural e consequentes modos de vida (Brandão, 2007).

Isso levou à expropriação de trabalhadores(as) das grandes propriedades, mas, por outro lado, contou-se com um grande e crescente número de pequenos agricultores que conseguiram de maneiras distintas, manter a capacidade de organizar uma atividade produtiva (Wanderley, 2011). A lógica do capital flexível conduzido, sobretudo, pelas unidades de expansão do agronegócio, foi questionada, pois não se pode desconsiderar a resistência ativa de grupos e comunidades expropriados. Nas palavras de Brandão (2007), "um campesinato modernizado, em parte cativo, mas em parte ainda livre diante do poder do agronegócio, não apenas sobrevive, mas se reproduz com sabedoria" (p. 42).

Entendendo essa diversidade de atores e contextos, que torna impossível recorrer aos processos de generalização e comparação, é possível perceber que na história do Brasil o campesinato foi construído particularmente como uma economia. A tendência economicista concebeu-o como um modo de produção com lógica própria ou como resultado de determinações impostas pela lógica do capital, tratando o camponês como um pequeno produtor (Woortmann, 1990).

Estudos que passaram a considerar o discurso sobre a campesinidade, Woortmann (1990) resultou no afastamento da tendência economicista. Os interesses voltaram-se para análise de valores, representações e subjetividades, mais do que para relações sociais objetivas. Partiu-se do entendimento de que "modelos nunca são 'iguais à realidade', se por essa última se entende a concretude histórica que é, essencialmente, movimento" (p. 13), não sendo possível afirmar a existência de camponeses puros.

Tendo por base essa discussão sobre o campesinato, na contemporaneidade, emergiu a discussão de um novo nominalismo, na identificação de novos atores sociais na cena política, sob novas configurações, como povos ou comunidades tradicionais: seringueiros, quilombolas, ribeirinhos, caiçaras, pescadores, dentre outros. Na opinião de alguns autores, a exemplo de Almeida (2007), esse novo nominalismo incide na morte do campesinato, ou seja, na "morte de um sistema de pensamento", leia-se "fim de um código". Muito embora, seja preciso ressalvar, que "as peças que esse código [campesinato] organizava no passado, contudo, estão ainda em circulação".

${ }^{6}$ Dada a variedade de tipos explorados, para maior aprofundamento, consultar Wolf (2003). 
É nesse sentido que o autor esclarece que o que está em jogo é "o fim de uma imagem camponesa que aglutinava traços em um fato social total e que inseria esse fato social total em uma história universal" (p. 172, grifo nosso).

Para Moraes e Vilela (2013), a emergência de um novo nominalismo diz respeito ao movimento teórico de crítica e desconstrução de meta-narrativas e do próprio conceito de camponês. No entanto, não concebem como exclusão de um discurso por outro, mas como possibilidades de diálogos, não existindo uma única e correta maneira de definição do camponês, sendo preciso conhecer e analisar cada realidade, em suas várias dimensões, inter-relações, mudanças e permanências.

Dessa maneira, assim como o conceito de rural, é possível apontar que a compreensão sobre as populações rurais foi ampliada. Passaram a serem percebidas como mais do que instrumentos da produção agrícola (Martins, 2001), por meio de perspectivas que ultrapassam a dimensão econômica e do corpo associado primordialmente ao trabalho. Bourdieu (2006), nesse sentido, refere-se ao camponês como ser de cultura em que o seu corpo expressa seus sistemas culturais, não apenas ligado às esferas do trabalho e produtivista. As análises do autor chamam a atenção para a subjetividade e posições econômicas, sociais, de gênero, políticas, dentre outras.

Para Ferreira (2008, p. 41), é possível verificar que, na constituição imaginária do Texto Brasileiro sobre o Rural (TB), o camponês tem um corpo normatizado, domesticado, instituído, instrumentalizado numa função. $\mathrm{O}$ trabalho desenvolvido por esse autor foi então de desconstrução e de desnaturalização desse corpo, pensando-o em termos de conexões, fluxos e devires. Trouxe contribuições de pesquisadores clássicos e atuais ${ }^{7}$, para demonstrar esse imaginário sobre "copos-mutilados por um ideário acadêmico sobre o Outro e não com o Outro", em sociedades camponesas que foram reduzidas ao parentesco, à economia da troca, ao dote, às relações vicinais, ao compadrio, à herança e à repressão, enfim, não vistas pelo campo do desejo.

O camponês torna-se folclore [...] objeto legitimado por uma identidade cultural isenta de suas pulsões e vibrações. Um personagem quase nulo de suas paixões, pois o que vale para muitos teóricos das sociedades camponesas são praticamente as estruturas e as funções e não as intensidades e as paixões [...] sufocando o novo, a mudança, o intempestivo, o desejo, outros modos de vida (Ferreira, 2008, p. 58, grifo do autor).

Foi exatamente por ter sido contrário a essa visão do camponês isento de pulsões, tendo se voltado para as contradições envoltas no homem do campo e em seu corpo, por meio da consideração de sua subjetividade, que Pierre Bourdieu inaugurou o novo na literatura sobre sociedades camponesas. Sua leitura ajuda a pensar "um camponês agente e não agido", possibilitando ampliar discussões sobre a sexualidade - que com raras exceções estão centradas na heterossexualidade e na prevalência de um discurso singular, funcional e ligado à reprodução das espécies - e sobre outros "afetos indizíveis", que continuam ausentes das discussões teóricas sobre o rural (Ferreira, 2008, pp. 60-61, grifo do autor).

A respeito dessa ausência, Gontijo e Erick (2015) apontaram a pouca produção relacionada à diversidade sexual e de gênero e particularidades da sexualidade em contextos rurais e interioranos no âmbito das ciências humanas. A partir de uma pesquisa bibliográfica, verificaram que se sobressai nos artigos e textos analisados temas como a organização social vinculada aos aspectos econômicos, questões morais relativas à família e aos arranjos familiares, sendo a sexualidade relegada à vida urbana e considerada uma temática periférica, seja por conta dos ideais desenvolvimentistas e heteronormativos, seja porque essas temáticas não faziam parte da agenda de pesquisas ou ainda por não serem consideradas discursos relevantes.

Na contemporaneidade, um discurso relevante que não pode deixar de ser referido diz respeito à parcela majoritária da população que vive em situação de pobreza e insegurança, que se encontra presente nos meios rurais (Oliveira, 2013). Para Ximenes e Moura Junior (2013), as realidades em condições mais precárias do território brasileiro são as áreas rurais, onde se encontram a maioria da população com os menores índices de qualidade quando com-

${ }^{7}$ Em “Os afectos mal-ditos: o indizível nas sociedades camponesas" (Ferreira, 2008), o autor especifica os diversos modelos, teorias e teóricos, que o ajudam na construção de sua crítica sobre o imaginário instituído sobre as sociedades camponesas. 
parado a outros países e, de acordo com Albuquerque (2001), onde se localizam as maiores diferenças sociais. Ali a proporção de pobres é bem mais significativa, sendo que a maioria sofre carências econômicas e sociais de diversas ordens, historicamente marginalizados por um modelo de desenvolvimento produtivo e subjetivo e simbólico com forte viés urbano (Dedecca, 2013).

Por tudo isso, no contexto das ruralidades contemporâneas e em meio às novidades, transformações e teses que versam sobre o tema, ganha ênfase a pobreza nos meios rurais brasileiros. Conforme Batista e Neder (2015) a pobreza nos meios rurais guarda especificidades, especialmente relacionadas ao grau de vulnerabilidade das famílias, pois, tende a ser mais expressiva seja em relação ao critério da renda, seja ainda em relação às dificuldades de acesso a serviços básicos de saúde, educação, saneamento básico, dentre outros, apoiando as teses da multidimensionalidade da pobreza. Corrobora com essa posição, a pesquisa realizada por Direito, Lício, Marson e Frutuoso (2015), que confirma que a pobreza rural tem dimensões próprias, como a dificuldade de acesso a serviços públicos básicos, moradias mais precárias, menos anos de estudo e menor capacidade de geração de renda, desemprego, e dependência de programas sociais de transferência de renda. Sendo ainda uma pobreza não homogênea, pois existem diferentes condições de vida e enfrentamento de desafios diferenciados em cada realidade.

Certamente são muitas as dificuldades ao tratar sobre o tema. As características aludidas demonstram o quanto discussões sobre a redução das desigualdades e a superação da pobreza no Brasil precisam pautar-se em diagnósticos, estratégias e ações que considerem as singularidades da situação social e econômica dos conhecidos como os pobres do campo (Mello, \& Oliveira, 2015).

Por meio da discussão apresentada, e considerando que o movimento de aproximação dos(as) psicólogos(as) com as ruralidades é recente, e, além disso, considerando que continuam ausentes, em certa medida, das próprias discussões teóricas sobre os estudos rurais, compreendemos o grande desafio colocado a estes(as) profissionais e aos cursos de formação em Psicologia de todo país, no sentido de se inserirem no debate e na qualificação do seu saber-fazer para atuarem junto às realidades dos povos e meios rurais no Brasil.

\section{Desafios e interpelações à Psicologia no encontro com os povos e meios rurais}

Ao recuperar os estudos historiográficos internacionais sobre a Psicologia Rural, Landini et al. (2015) fazem referência à obra inaugural de James Williams, em 1925, quando publicou, nos EUA, o livro Our rural heritage. The social psychology of rural development, um marco nos estudos nesse campo. Em 1926, o mesmo autor lança The expansion of rural life: the social psychology of rural development. Ambos os estudos tratam sobre o desenvolvimento rural à luz da Psicologia social. Enquanto o primeiro toma de análise as atitudes e crenças que conformam o patrimônio rural americano, cujas influências, na opinião do autor, recaem numa espécie de Psicologia nacional do povo americano; o segundo mostra esse mesmo patrimônio rural em processo de adaptação às novas condições e transformações vividas na sociedade americana, a partir do último quartel do século XIX, com o avanço e exigências da tecnificação e industrialização urbana.

$\mathrm{Na}$ realidade brasileira, os primeiros trabalhos envolvendo os meios rurais datam de 1940, realizados por Helena Antipoff, com a educação de crianças no campo no estado de Minas Gerais, sistematizados na obra "Educação rural", publicada em 1992, pelo Centro de Documentação e Pesquisa Helena Antipoff (Martins, Augusto, \& Antunes-Rocha, 2011). Ao longo dos anos 1970 e 1980, começam a despontar trabalhos no âmbito da Psicologia Social Comunitária na região Sudeste do país, e em seguida, na Nordeste, envolvendo reflexões, pesquisas e intervenções, por meio da extensão universitária, junto a populações específicas, como comunidades rurais, assentamentos sem-terra, mutirões e cooperativas rurais e até mesmo tribos indígenas (Leite et al., 2013).

Sem a pretensão de sumariar, esgotar e tomar em análise a produção psicológica brasileira sobre o tema, apresentaremos um rápido panorama sobre os estudos publicados em periódicos científicos nacionais e internacionais de Psicologia nos últimos 25 anos, período em que o debate dos estudos sobre ruralidades se consolida no país.

Nos anos 1990 registram-se oito estudos envolvendo temáticas relacionadas ao rural. Nesse sentido, destaca-se a investigação de Albuquerque (1996), pelo levantamento bibliográfico que realiza junto às revistas da Associação Americana de Psicologia (APA) e eventos de Psicologia no Brasil, acerca 
dos trabalhos que relacionam Psicologia Social e o mundo rural, inclusive para orientar agendas de pesquisa. Os temas identificados no seu estudo foram: saúde mental, família, atitudes, ergonomia e variações individuais, tecnologia, política econômica, satisfação e qualidade de vida, extensão agrária, conceitos/definições e ecologia. Dois aspectos merecem destaque nesta avaliação: apesar de poucos estudos encontrados e certa diversidade de temas, menos ainda eram os trabalhos em Psicologia que incluam modelos teóricos em termos do entendimento sobre rural; por outro lado, indica a necessidade de ampliar estudos na área, considerando que, no Brasil, há um campo amplo de investigação a ser explorado, particularmente no Nordeste.

As demais publicações sobre rural nos anos 1990 trataram basicamente dos seguintes temas de investigação: análises sobre o cooperativismo agrário, com foco nos aspectos psicossociais e formas de organização envolvidos (por exemplo: Albuquerque, Clemente, \& Meneses, 1996); análises e compreensão das condições e os efeitos do trabalho, quer seja junto aos pequenos produtores rurais (Veloso, 1996), quer seja na agricultura moderna, particularmente no ramo da fruticultura e produção de rosas (Augusto, 1998), ou mesmo em torno da migração e adaptação no meio urbano por trabalhadores de lavouras de cana (Romaneli, \& Bezerra, 1999), além da análise dos papéis sociais de idosos rurais e as condições psicossociais que os diferenciam dos aposentados urbanos (Albuquerque, Lobo \& Raimundo, 1999).

Na década de 2000 observa-se o incremento de publicações sobre rural na Psicologia em periódicos científicos nacionais e internacionais, especialmente com estudos no âmbito da Psicologia Social. Foram 41 artigos no período, com destaque para o maior número de publicações a partir de 2006. Os temas de interesse que marcaram esse período foram: assentamentos rurais, trabalhadores rurais, militância e movimentos sociais de luta pela terra; cooperativas agrárias e associativismo rural; avaliação de programas e políticas para o setor, a exemplo do Programa Nacional de Fortalecimento da Agricultura Familiar (Pronaf); assistência técnica e extensão rural; desenvolvimento infantil-juvenil e envelhecimento no meio rural; educação no meio rural; bem-estar subjetivo e saúde mental no meio rural; trabalho escravo; aspectos relacionados à gestão da água e a questão da seca; transformações no meio rural; agronegócio e transformação no mundo do trabalho rural; mulheres trabalhadoras rurais; gênero e ruralidade; produção cultural e meio rural; e discussões teóricas e metodológicas acerca de investigações no meio rural.

De 2010 até 2015 foram publicados 28 artigos, mantendo praticamente os mesmos temas investigados na década anterior em interface com as categorias da Psicologia social, apesar do surgimento de novo temas de investigação: populações quilombolas, comunidades ribeirinhas, área de conservação e preservação ambiental, identidade cabocla, programas de transferência de renda (Programa Bolsa Família) e pobreza rural, uso de agrotóxicos e efeitos à saúde do trabalhador rural, prática profissional do psicólogo em meio rural, além da maior presença de trabalhos sobre desafios metodológicos e conceituais acerca do mundo rural.

No geral, apesar da grande variedade de temas na trajetória da produção psicológica brasileira acerca do rural, observou-se certa centralidade de estudos envolvendo o trabalho rural, a organização dos trabalhadores rurais e seus efeitos em torno das categorias na Psicologia social a partir da dualidade rural-urbano: identidade, relações grupais, socialização e modos de vida no campo, organização política e comunitária, produção de sentidos, processos de subjetivação, representações sociais, percepção, atitudes, valores, crenças, dentre outros.

Sem a pretensão de esgotar o debate acerca do encontro da Psicologia com os povos e meios rurais, destaca-se a necessidade do aprofundamento e apropriação da reflexão crítica sobre os estudos rurais no Brasil. Sem dúvida, a inserção profissional dos psicólogos(as) e a produção de conhecimento nesse campo passa pela necessidade de ultrapassar a dualidade rural-urbano, penetrando nos "fundamentos últimos e históricos do conhecimento que a originou", para "descortinar e explicar as bases rurais de produção do ser social" (Martins, 1986, p. 38). Deste modo, articula-se nessa direção, o aprofundamento sobre as diferentes abordagens conceituais, entre elas, as discussões teóricas sobre o novo rural brasileiro (Silva, 1982; 1987; 1997), sobre ruralidades contemporâneas, que versam sobre o tema da revalorização do rural por meio de diferentes perspectivas: a) consideração de sua diversidade e potencialidades; b) afirmação de novas ruralidades; c) expressões de identidades sociais no mundo rural; d) plurali- 
zação da ideia de rural, com destaque para a desigualdade do seu desenvolvimento no Brasil; além da e) compreensão das influências geradas e difundidas por distintas instituições nacionais e internacionais, e organismos multilaterais que tratam sobre o tema (Carneiro, 1998, 2005, 2008; Moraes, 2014; Moreira, 2003, 2005; Veiga, 2006; Wanderley, 2000; 2001; 2011). Foram poucos os estudos que tocaram, em alguma medida nesses pontos, inclusive incorporando as reflexões dos autores que somam ao debate sobre os estudos rurais no Brasil.

A realização do "Seminário Nacional - A Questão da Terra: desafios para a Psicologia”, em 2006, pelo Conselho Federal de Psicologia (CFP), trouxe, sem dúvida, maior aproximação do tema à profissão, mesmo que ainda permeado, em grande medida, pela leitura do rural como lugar e espaço. Os temas discutidos foram: a) A questão da terra: urgências e desafios para a sociedade brasileira; b) $\mathrm{O}$ espaço como substrato para constituição da subjetividade; c) A subjetividade constituída nas relações com a terra; d) A questão da terra como desafio para a Psicologia; e) A luta pela terra ou por um lugar no mundo.

Com a publicação do Caderno de Referências Técnicas para Atuação dos(as) Psicólogos(as) em Questões Relativas à Terra, pelo CFP (2013), e com a publicação da coletânea "Psicologia e contextos rurais", organizada por Leite e Dimenstein (2013), imprime-se novo fôlego às discussões da Psicologia sobre ruralidades. Nas duas obras o rural é abordado em suas várias expressões e realidades (conceitos, cenários e populações), com ênfase no contexto brasileiro, refletindo em leituras interdisciplinares que se aproximam das discutidas na sessão anterior a partir de Albuquerque (2001, 2002), Carneiro (2005), Moreira (2005) e Wanderley (2001).

Assim, percebe-se na trajetória desses 25 anos da produção psicológica brasileira sobre rural que, com o amadurecimento e aprofundamento das investigações sobre o tema, novas temáticas foram incorporadas. Porém, avaliamos que é necessário avançar ainda mais com a apropriação do debate teórico político sobre ruralidades contemporâneas, para além das novas formas de organização da atividade agrícola, como por exemplo, o neorruralismo, a multifuncionalidade da agricultura e dos territórios, limites dos conceitos de meio rural e de sociedade rural, populações rurais repensadas, dentre outros (Moraes, 2014).
Outro desafio diz respeito à apropriação dos marcos legais de políticas, para além do Pronaf, embora tímido apesar de presente na produção psicológica. Nesse sentido, é preciso incorporar políticas como Programa Territórios da Cidadania, que articulou programas como a Política Nacional de Assistência Técnica e Extensão Rural para Agricultura Familiar e Reforma Agrária (Pnater), Programa Nacional de Assistência Técnica e Extensão Rural na Agricultura Familiar e na Reforma Agrária (Pronater), Plano Nacional de Reforma Agrária (PNRA) e Comunidades Quilombolas (Moraes, 2014), dentre outras.

É preciso que se reconheça a complexidade do universo social em questão, entendendo rural como "um mundo dinâmico de sociabilidades, de valores rurais e urbanos e como espaço de disputas e assimetrias culturais e políticas" (Moreira, 2005, p. 87), onde se constrói um jogo de interesses e disputas no território, um espaço de exercício da política e a expressão de poderes assimétricos. Isso requer de psicólogos(as) que problematizem processos, tensões, diferenças e identidades sociais meio as disputas e diferentes interesses projetados no território: entre, por exemplo, Ibama, Incra e prefeituras; entre proprietários de terra e empresários do agronegócio; entre movimentos ambientalistas e da reforma agrária etc. (Moreira, 2005).

Portanto, a entrada desses(as) profissionais no debate sobre rural, requer a compreensão de uma abordagem: a) plural, que perceba rural como transformação, e não meramente como um cenário ou espaço geográfico; b) interdisciplinar, por fazer uso de diferentes conceitos e olhares desenvolvidos por diferentes disciplinas; e mesmo c) transdisciplinar, pela possibilidade de construir, a partir do cruzamento de diferentes olhares e saberes disciplinares, uma nova perspectiva que responda a diversidade desse campo.

A partir dessas considerações, entende-se que a reflexão brasileira sobre Psicologia e ruralidades, possui o desafio de um maior investimento em planos de pesquisas que deem atenção a variedade de "processos", "encontros", "contatos", "interações", "trocas", enfim, dos hibridismos (Burke, 2003, p. 16) ou, de acordo com Canclini (2008), dos processos de hibridização que irrompem, desarticulam e reformulam conceitos. Assim, talvez, possamos apreender a diferença consubstanciada na emergência de identidades sociais múltiplas a partir de novas relações de 
alteridade que se estabelecem nos contextos rurais. "Recusar o enclausuramento em nossos particularismos, a fim de expor-se a outras perspectivas [...] articulação adequada entre cultura, pertencimento e diálogo", torna-se, portanto, uma exigência ética no nosso modo de fazer pesquisa nesse campo (Marc-Antoine Vallée, 2014, p. 38). Como lembra Velho (2009), "são diversas as ocorrências concretas que se apresentam em nosso meio rural" com uma "variedade de manifestações locais de agrupamentos e classes" (p. 91). É preciso, nesse sentido, considerar a pluralidade de conceitos sobre rural e categorias êmicas e éticas na referência a populações rurais/ urbanas e intervir na complexidade de relações, identidades e heterogeneidades.

Não sendo mais possível desconhecer a diversidade do rural que, além de um espaço de trabalho, produção e sobrevivência, refere-se a espaços de vida, interação e expressão cultural (Otero, 2013) e tendo em vista ser essa uma temática nova na área, cabe à Psicologia problematizar sobre os seus meios de acessar essas realidades. Os modos de fazer pesquisa precisam ser coerentes, amparando-se em perspectivas associadas a diálogos e construções, que permitam perceber as variedades e singularidades dos meios rurais, entendendo que "método não é o meio de acessar algo, mas sim de se (re) construir no que estudamos e pesquisamos" (Spink, Medrado \& Méllo, 2014, p. 27).

Sobre a formação profissional dos(as) psicólogos(as), é necessário a introdução de debates interdisciplinares nos cursos de graduação que versem sobre ruralidades. Além disso, estágios, cursos de extensão e projetos de pesquisa na área precisam ser incorporados, no sentido de permitir o contato do estudante com conceitos, categorias e diretrizes integrados à vivência nas realidades rurais com seus povos. Para Carneiro (2005, p. 13), "um olhar histórico sobre a produção do conhecimento sobre o mundo rural se faz cada vez mais necessário para respondermos aos impasses que a complexidade da realidade tem imposto à teoria". Psicólogos(as), nesse sentido, são desafiados a conhecer a diversidade de representações, noções, e conceitos instrumentalizados, a lidar com a atualização da definição de rural e a contribuir para os estudos das ruralidades na sociedade contemporânea. Considerando que "as possibilidades de atuação do psicólogo no que diz respeito ao meio rural e toda diversidade que ele se reveste são múltiplas" (Leite el al., 2013, p. 49), é preciso incluir e avançar no saber-fazer psicológico meio as ruralidades temas como: relações de gênero e de gerações; modos de subjetivação, processos psicossociais e identitários; processos sociais e culturais; concentração fundiária; lutas sociais e a questão da terra; movimentos sociais rurais; processos sociais na transformação da realidade agrária; organizações sociais de classe; diferentes matrizes teóricas que refletem sobre a diversidade do campesinato; contradições do modelo produtivista de modernização da agricultura; multifuncionalidade da agricultura familiar; categorias: infância, adolescência, juventude e velhice; sexualidades; violências; drogas; famílias rurais; pobreza rural; religião; desenvolvimento rural sustentável; processos de assistência técnica e de extensão rural.

\section{Considerações Finais}

Na última década, a produção de conhecimentos que tratou a relação da Psicologia com os contextos rurais foi permeada pela diversidade de temáticas, espaços, populações, realidades e fenômenos, se comparada aos anos anteriores. O crescimento de estudos nesse campo nos últimos anos é resposta, em grande medida, à evidente expansão da atuação de psicólogos(as) junto a realidade de municípios pequenos e contextos rurais, em função de sua integração nas políticas sociais, bem como ao próprio processo de expansão da formação graduada e pós-graduada em Psicologia, com abertura de linhas de pesquisa e projetos de investigação envolvendo os povos e meios rurais.

Apesar disso, fica patente o pouco trânsito da nossa ciência e profissão nos debates sobre os sentidos de rural contemporâneo como categoria de reflexão teórica, muito embora, registra-se a preocupação para que se aproprie das diferentes categorias e significações que vêm sendo estabelecidas pelas diferentes disciplinas que constituem o campo dos estudos rurais, de modo a construir parâmetros e norteadores coerentes com as múltiplas realidades que permeiam os meios rurais brasileiros.

É necessária, portanto, a construção de um recorte crítico capaz de fortalecer a discussão acerca da presença da Psicologia no mundo rural. Mas, sobretudo, intensificar o debate sobre o compromisso ético-político da profissão junto aos diversos aspectos que afligem a vida dos povos rurais no Brasil. 


\section{Referências}

Albuquerque, F. J. B. (2001). Aproximación metodológica desde la psicología social a la investigación en zonas rurales. Estudios Agrosociales y Pesqueros, (191), 225-233. Recuperado de http://www.magrama.gob.es/ministerio/pags/biblioteca/revistas/pdf_reeap\%2Fr191_09.pdf

Albuquerque, F. J. B. (1996). Aspectos psicossociais do mundo agrário. Revista de Psicologia, 13/14 (1/2), 69-75. Recuperado de http://repositorio.ufc.br/ri/bitstream/riufc/11106/1/1995_art_fjbalbuquerque.pdf

Albuquerque, F. J. B. (2002). Psicologia social e formas de vida rural no Brasil. Psicologia: Teoria e Pesquisa, 18(1), 37-42. https://doi.org/10.1590/S0102-37722002000100005

Albuquerque, F. J. B., Clemente, M., \& Menezes, S. (1996). Aspectos psicossociais na formação de cooperativas agrárias. Psico, 27(1), 207-214.

Albuquerque, F.J. B., Lobo, A. L., \& Raimundo, J.S. (1999). Análise das repercussões psicossociais decorrentes da concessão de benefício rurais. Psicologia: Reflexão e Crítica, 12(2), 503-519. http://dx.doi.org/10.1590/S0102-79721999000200016

Alentejano, P. R. (2003). As relações campo-cidade no Brasil do século XXI. Terra Livre, 2(21), 25-39.

Almeida, M.W. (2007). Narrativas agrárias e morte do campesinato. Ruris, 1 (2), Campinas: Unicamp, 157-186. Recuperado de http://www.ifch.unicamp.br/ojs/index.php/ruris/article/view/656/523

Augusto, R. C. (1998). O significado do trabalho e a construção da consciência. Cadernos de Psicologia, 5(7), 39-47.

Batista, H. R., \& Neder, H. D. (2014). Efeitos do Pronaf sobre a pobreza rural no Brasil (2001-2009). Revista de Economia e Sociologia Rural, 52 Supl. 1, 147-166. https://doi.org/10.1590/S0103-20032014000600008

Blume, R. (2004). Território e ruralidade: a desmistificação do fim do rural. (Dissertação de mestrado). Universidade Federal do Rio Grande do Sul, Porto Alegre, RS.

Bourdieu, P. (2006). O camponês e seu corpo. Revista de Sociologia e Política, (26), 83-92. https://doi.org/10.1590/S0104-44782006000100007

Bourdieu. P. (2009). O poder simbólico. Rio de Janeiro, RJ: Bertrand Brasil.

Brandão, C. R. (2007). Tempos e espaços nos mundos rurais do Brasil. Ruris, 1(1), 37-64. Recuperado de: http:// www.ifch.unicamp.br/ceres/037-064-carlos_rodrigues.pdf

Brasil. (2008, 26 fev)Decreto de 25 de fevereiro de 2008. Institui o Programa Territórios da Cidadania e dá outras providências. Diário Oficial da União.

Brumer, A., \& Santos, J. V. T. (2006). Estudos agrários no Brasil: modernização, violência e lutas sociais (desenvolvimento e limites da Sociologia Rural no final do século XX). Revista Nera, 9(9), 49-72. Recuperado de: http:// www2.fct.unesp.br/nera/revistas/09/Brumer.pdf

Burke, P. (2003). Hibridismo cultural. São Leopldo, RS: Editora Unisinos.

Camargo, R. A. L., \& Oliveira, J. T. A. (2012). Agricultura familiar, multifuncionalidade da agricultura e ruralidade: interfaces de uma realidade complexa. Ciência Rural, 42(9), 1707-1714. https://doi.org/10.1590/S0103-84782012005000068

Canclini, N. G. (2008). Culturas híbridas: estratégias para entrar e sair da modernidade (4a ed). São Paulo, SP: Edusp.

Carmo, R. M. (2009). A construção sociológica do espaço rural: da oposição à apropriação. Sociologias, Porto Alegre, (21), 252-280. Recuperado de: http://www.scielo.br/pdf/soc/n21/11.pdf

Carneiro, M. J. (2005). Apresentação. In R. J. Moreira (Org.), Identidades sociais: ruralidades no Brasil contemporânеo (pp. 7-13). Rio de Janeiro: DP\&A.

Carneiro, M. J. (2008). "Rural" como categoria de pensamento. Ruris, 2(1), 9-38. Recuperado de http://www.ifch. unicamp.br/ojs/index.php/ruris/article/view/661/528

Carneiro, M. J. (1998). Ruralidade: novas identidades em construção. Estudos Sociedade e Agricultura, (11), 53-75. https://doi.org/10.1590/S1517-45222009000100011

Conselho Federal de Psicologia - CFP. (2013), Centro de Referência Técnica em Psicologia e Políticas Públicas. Referências Técnicas para Atuação das(os) Psicólogas(os) em Questões Relativas a Terra. Brasília, DF: o autor. Recuperado de: http://site.cfp.org.br/publicacao/referencias-tecnicas-para-atuacao-dasospsicologasos-em-questoes-relativas-a-terra/ 
Dedecca, C. S. (2013). Contribuições para a agenda da política de combate à pobreza rural. In C. Miranda, \& B. Tiburcio (Orgs.), A nova cara da pobreza rural: desenvolvimento e a questão regional (pp. 19-32. Série Desenvolvimento rural sustetável, vol. 17). Brasília, DF: Instituto Interamericano de Cooperação para a Agricultura. Recuperado de http://www.iicabr.iica.org.br/wp-content/uploads/2014/03/S\%C3\%A9rie-DRS-vol-17.pdf

Direito, D., Lício, E., Marson, N., \& Frutuoso, J. R. (2015). Perfil socioeconômico das pessoas e famílias residentes no meio rural sob a ótica do cadastro único para programas sociais. In J. Mello (Org.), A inclusão produtiva rural no Brasil sem miséria: o desafio da superação da pobreza no campo (pp. 136-159. Cadernos de Estudos Desenvolvimento Social em Debate, vol. 23).

Ferreira, P. R. (2008). Os afectos mal-ditos: o indizível nas sociedades camponesas. São Paulo, SP: Anpocs.

Godoi, E. P., Menezes, M. A., \& Marin, R. A. (Orgs.). (2009). Diversidade do campesinato: expressões e categorias (Vol. 2, Estratégias de reprodução social). São Paulo, SP: Editora UNESP.

Gontijo, F., \& Erick, I. (2015). Diversidade sexual e de gênero, ruralidade, interioridade e etnicidade no Brasil: ausências, silenciamentos e... exortações. Aceno, 2(4), 24-40. Recuperado de http://periodicoscientificos.ufmt.br/ojs/ index.php/aceno/article/view/3181

Haas, J. M., \& Hillig, C. H. (2009). A abordagem da pobreza rural no contexto das novas ruralidades. $48^{\circ}$ Congresso da Sociedade Brasileira de Economia, Administração e Sociologia Rural. Congresso realizado em Campo Grande. Recuperado de: http://www.sober.org.br/palestra/15/94.pdf

Landini, F, Saforcada, E., Quintanar, C. S., Almaral, M. I., Wiesenfeld, E., Long, N. et al. (2015). Hacia una psicología rural latinoamericana. Buenos Aires: Clacso.

Leite, J. F., \& Dimenstein, M. (Orgs.). (2013). Psicologia e contextos rurais. Natal, RN: EDUFRN.

Leite, J. F., Macedo, J. P. S., Dimenstein, M., \& Dantas, C. (2013). A formação em Psicologia para a atuação em contextos rurais. In J. F. Leite, M. Dimenstein (Orgs.), Psicologia e contextos rurais (pp. 27-55). Natal: EDUFRN.

Lindner, M., Alves, F. D., \& Ferreira, E. R. (2009). Presença da ruralidade em municípios gaúchos: o exemplo de Silveira Martins, RS. In XIX Encontro Nacional de Geografia Agrária (pp. 1-15). Recuperado de http://www.geografia.fflch.usp.br/inferior/laboratorios/agraria/Anais\%20XIXENGA/artigos/Lindner_M.pdf

Macedo, J. P., \& Dimenstein, M. (2011). Expansão e interiorização da Psicologia: reorganização dos saberes e poderes na atualidade. Psicologia: Ciência e Profissão, 31(2), 296-313. https://doi.org/10.1590/S1414-98932011000200008

Marc-Antoine Vallée. (2014). In. Savianni Filho, J. (Ed./Trad.). Dossiê culturas partilhadas: pensadores do oriente e do ocidente refletem sobre a urgência de nos reconhecermos pelo olhar do outro. Cult. 17(196).

Martins, A. M., Augusto, R. C., \& Antunes-Rocha, M. I. (2011). Psicologia e educação rural na obra de Helena Antipoff: um olhar sobre o passado. Memorandum, 21, 88-104.

Martins, J. S (Org.). (1986). Introdução crítica à sociologia rural. São Paulo, SP: Hucitec.

Martins, J. S. (2001). O futuro da sociologia rural e sua contribuição para a qualidade de vida rural. Estudos Avançados, 15(43), 31-36. https://doi.org/10.1590/S0103-40142001000300004

Mattei, L. (2015). Considerações acerca de teses recentes sobre o mundo rural brasileiro. Revista de Economia e Sociologia Rural, 52 supl. 1, 105-124. https://doi.org/10.1590/S0103-20032014000600006

Mello, J., \& Oliveira, Y. R. (2015). Apresentação. In J. Mello. A inclusão produtiva rural no Brasil Sem Miséria: o desafio da superação da pobreza no campo (pp. 7-12. Cadernos de estudos desenvolvimento social em debate, vol. 23). Brasília, DF: Ministério do Desenvolvimento Social e Combate à Fome. Recuperado de http:/ / aplicacoes. mds.gov.br/sagirmps/ferramentas/docs/Caderno\%2023_\%20FINAL_910.pdf

Moraes, M. D. C. (2014, 11 set). Ruralidades, cultura, e desenvolvimento, no Brasil: provocações para um debate necessário. In Seminário Organização e Impactos da Cultura no Desenvolvimento. Regional. Rio de Janeiro, RJ: Ministério da Cultura.

Moraes, M. D. C., \& Vilela, S. L. O. (2013). Trilhas de um debate contemporâneo: ruralidades, campesinato, novo nominalismo. Revista FSA, 10(1), 59-85. Recuperado de http://www4.fsanet.com.br/revista/index.php/fsa/article/view/138/76

Moreira, R. J. (2003). Cultura, política e o mundo rural na contemporaneidade. Estudos Sociedade e Agricultura, 20, 113-143. Recuperado de http://rl.ufrrj.br/esa/V2/ojs/index.php/esa/article/view/232/228 
Moreira, R. J. (2005). Identidades sociais em territórios rurais fluminenses. In: R. J. Moreira (Org.), Identidades sociais: ruralidades no Brasil contemporâneo (pp. 65-88). Rio de Janeiro: DP\&A.

Oliveira, R. B. (2013). Evolução da pobreza na américa latina: velhas e novas caras. In C. Miranda, \& B. Tiburcio (Orgs.), A nova cara da pobreza rural: desenvolvimento e a questão regional (pp. 33-56. Série Desenvolvimento rural sustetável, vol. 17). Brasília, DF: Instituto Interamericano de Cooperação para a Agricultura. Recuperado de: http://www.iicabr.iica.org.br/wp-content/uploads/2014/03/S\%C3\%A9rie-DRS-vol-17.pdf

Otero, M. (2013). Prefácio IICA. In C. Miranda, \& H. Silva (Orgs.), Concepções da ruralidade contemporânea: as singularidades brasileiras (Série Desenvolvimento Rural Sustentável, Vol. 21). Brasília, DF: Instituto Interamericano de Cooperação para a Agricultura.. Recuperado de http://repiica.iica.int/DOCS/B3226P/B3226P.PDF

Romanelli, G., \& Bezerra, N. M. A. (1999). Estratégias de sobrevivência em famílias de trabalhadores rurais. Paidéia (Ribeirão Preto), 9(16), 77-87. https://doi.org/10.1590/S0103-863X1999000100008

Schneider, S. (1997). Da crise da sociologia rural à emergência da sociologia da agricultura: reflexões a partir da experiência norte-americana. Cadernos de Ciência \& Tecnologia, 14(2), 225-256. Recuperado de https://seer.sct. embrapa.br/index.php/cct/article/download/8970/5081.

Schneider, S. (2010). Situando o desenvolvimento rural no Brasil: o contexto e as questões em debate. Revista de Economia Politica, 30(3), 511-531. https://doi.org/10.1590/S0101-31572010000300009

Shanin, T. (2008). Lições camponesas. In E. T. Paulino, J. E. Fabrini (Orgs.), Campesinato e territórios em disputa (pp. 23-48). São Paulo, SP: Expressão Popular.

Silva, J. G. (1982). A modernização dolorosa: estrutura agrária, fronteira agrícola e trabalhadores rurais no Brasil. Rio de Janeiro: Zahar.

Silva, J. G. (1987). A nova dinâmica da agricultura brasileira. Campinas: Instituto de Economia, Universidade Estadual de Campinas.

Silva, J. G. (1997). O novo rural Brasileiro. Nova Economia, 7(1), 43-81. Recuperado de Http://www.geografia.fflch. usp.br/graduacao/apoio/Apoio/Apoio_Valeria/Pdf/O_novo_rural_brasileiro.pdf

Siqueira, D., \& Osório, R. (2001). O conceito de rural: una nueva ruralidad en América Latina? Buenos Aires: Consejo Latinoamericano de Ciencias Sociales.

Sorokin, P. A., Zimmerman, C. C., \& Galpin, C. J. (1981). Diferenças fundamentais entre o mundo rural e o urbano. In J. S. Martins, Introdução crítica à sociologia rural. São Paulo, SP: Hucitec.

Spink, M. J., Medrado, B., \& Méllo, R. P. (2014). Vinte e cinco anos nos rastros, trilhas e riscos de produções acadêmicas situadas. In M. J. P. Spink, \& J. I. M. Brigagão. A produção de informação na pesquisa social: compartilhando ferramentas Rio de Janeiro: Centro Edelstein de Pesquisas Sociais.

Veiga, J. E. (2007). Mudanças nas relações entre espaços rurais e urbanos. In: R. Piquet, \& E. Oliveira (Orgs.), Economia e território no Brasil contemporâneo. No prelo.

Veiga, J. E. (2006). Nascimento de outra ruralidade. Estudos Avançados, 20(57), 333-353. https:// doi.org/10.1590/S0103-40142006000200023

Veiga, J. E. (2001). O Brasil rural ainda não encontrou seu eixo de desenvolvimento. Estudos Avançados, 15(43), 101-119. https:// doi.org/10.1590/S0103-40142001000300010

Velho, O. G. (2009). O conceito de camponês e sua aplicação à análise do meio rural brasileiro. In A. W. Clifford, E. Malagodi, J. S. Cavalcant, M. N. B. Wanderley. (Orgs.). Camponeses brasileiros: leituras e interpretações clássicas (pp. 89-96). São Paulo: EdUnesp.

Veloso, T. M .G. (1996). A representação social do trabalho alugado ou "com a enxada nas costas e o coracao preso". Estudos de Psicologia.1(1), 26-35.

Wanderley, M. N. B. (2000). A emergência de uma nova ruralidade nas sociedades modernas avançadas: o "rural" como espaço singular e ator coletivo. Estudos Sociedade e Agricultura, (15), 87-145. Recuperado de rl.ufrrj.br/ esa/V2/ojs/index.php/esa/article/download/178/174

Wanderley, M. N. B. (2001). A ruralidade no Brasil moderno: por un pacto social pelo desenvolvimento rural. In N. Giarracca. ¿Una nueva ruralidad en América Latina? (pp. 31-44). Buenos Aires: Consejo Latinoamericano de Ciencias Sociales. 
Wanderley, M. N. B. (2015). O campesinato brasileiro: uma história de resistência. Revista de Economia e Sociologia Rural, 52 supl.1, S025-044. https://doi.org/10.1590/S0103-20032014000600002

Wanderley, M. N. B. (2011). Um saber necessário: os estudos rurais no Brasil. Campinas: Editora da Unicamp.

Wanderley, M. N. B., \& Favareto, A. (2013). A singularidade do rural brasileiro: implicações para as tipologias territoriais e a elaboração de políticas públicas. C. Miranda, \& H. Silva. (Orgs.). Concepções da ruralidade contemporânea: as singularidades brasileiras (pp. 413-457. Série Desenvolvimento Rural Sustentável, Vol. 21). Brasília, DF: Instituto Interamericano de Cooperação para a Agricultura.

Welch, C. A., Malagodi, E., Cavalcanti, J. S. B., \&Wanderley, M. N. B. (Orgs.). (2009). Camponeses brasileiros: leituras e interpretações clássicas (Vol. 1). São Paulo, SP: Editora UNESP.

Wolf, E. (2003). Tipos de campesinato latino-americano: uma discussão preliminar. In B. Feldman-Bianco, G. L. Ribeiro (Org.), Antropologia e poder (pp. 114-117). Brasília: EdUnB.

Woortmann, E. (1995). Teorias do campesinato. In E. Woortmann. Herdeiros, parentes e compadres (pp. 30-66). São Paulo: Hucitec.

Woortmann, K. (1990). Com parente não se neguceia: o campesinato como ordem moral.. Brasília, DF, UNB.

Ximenes, V. M., \& Moura Júnior, J. F. (2013). Psicologia comunitária e comunidades rurais do Ceará: caminhos, práticas e vivências em extensão universitária. In J. F. Leite, \& M. Dimenstein (Org.), Psicologia e contextos rurais (pp 453-476). Natal: EDUFRN.

\section{Kátya de Brito e Silva}

Graduada em Psicologia pela Universidade Federal do Piauí. Mestre em Políticas Públicas pela Universidade Federal do Piauí, Parnaíba - PI, Brasil. E-mail: katyabrito.s@gmail.com

\section{João Paulo Macedo}

Mestre e Doutor em Psicologia pela Universidade Federal do Rio Grande do Norte. Professor dos Programas de Pós-Graduação em Psicologia e em Políticas Públicas da Universidade Federal do Piauí, Parnaíba - PI, Brasil. E-mail: jpmacedo@ufpi.edu.br

Endereço para envio de correspondência:

Universidade Federal do Piauí, campus Ministro Reis Velloso, Departamento de Psicologia. Av. São Sebastião, 2819, Reis Veloso. CEP: 64202-020 -

Parnaíba - PI, Brasil.

Recebido 06/08/2016

Aprovado 14/05/2017

Como citar: Silva, K B., \& Macedo J. P. (2017). Psicologia e ruralidades no Brasil: contribuições para o debate. Psicologia: Ciência e Profissão, 37(3), 815-830. https://doi.org/10.1590/1982-3703002982016

How to cite: Silva, K B., \& Macedo J. P. (2017). Psychology and ruralities in Brazil: contributions for the debate. Psicologia: Ciência e Profissão, 37(3), 815-830. https://doi.org/10.1590/1982-3703002982016

Cómo citar: Silva, K B., \& Macedo J. P. (2017). Psicología y ruralidades en Brasil: contribuciones al debate. Psicologia: Ciência e Profissão, 37(3), 815-830. https://doi.org/10.1590/1982-3703002982016 